\title{
Coagulation and Placenta-Mediated Complications
}

\author{
Ian A. Greer, M.D., F.R.C.P. (Glas), F.R.C.P.E., F.R.C.P., F.R.C.P.I., F.F.S.R.H., \\ F.C.C.P., F.R.C.O.G., F.Med.Sci., ${ }^{1}$ Anat Aharon, Ph.D., ${ }^{2,3}$ Benjamin Brenner, \\ M.D., ,2,3* and Jean-Christophe Gris, M.D., Ph.D. ${ }^{4}$ \\ ${ }^{\prime}$ Faculty of Health $\mathbb{E}^{2}$ Life Sciences, University of Liverpool Foundation Building, Liverpool, UK; \\ ${ }^{2}$ Department of Hematology and Bone Marrow Transplantation, Rambam Health Care Campus, Haifa,

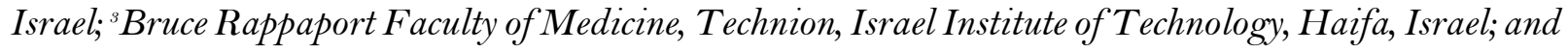 \\ ${ }^{4}$ Department of Hematology, Centre Hospitalier Universitaire, Nîmes, France
}

\begin{abstract}
Pregnancy is a physiological hypercoagulable state, preparing the mother for the hemostatic challenge of delivery. However, this is associated with an increased risk of venous thrombosis and placenta-mediated complications, which present major challenges for mother and fetus. Although these conditions are heterogeneous in their pathophysiology, hereditary and acquired thrombophilia has been associated with recurrent pregnancy loss and gestational vascular complications, such as early-onset pre-eclampsia and placental abruption. Prevention of such placenta-mediated complications, which collectively complicate up to $15 \%$ of pregnancies, is a major issue for women's health. Prospective interventional studies stratified by current knowledge of pathophysiological mechanisms related to placental and systemic hemostatic alterations will impact on the management of pregnancies at risk of these complications.
\end{abstract}

KEY WORDS: Placenta-mediated complications, recurrent pregnancy loss, thrombophilia

\begin{abstract}
Abbreviations: APC, activated protein C; APLS, anti-phospholipid syndrome; FGR, fetal growth restriction; Flt-1, fmsrelated tyrosine kinase 1; FVL, factor V Leiden; GVC, gestational vascular complications; GWAS, genome-wide association study; LMWH, low-molecular-weight heparins; PAI-1, plasminogen activator inhibitor-1; PGM, prothrombin gene mutation; SGA, small for gestational age; TF, tissue factor; TFPI, tissue factor pathway inhibitor.
\end{abstract}

Citation: Greer IA, Aharon A, Brenner B, Gris JC. Coagulation and Placenta-Mediated Complications. Rambam Maimonides Med J 2014;5 (4):eo034. doi:10.5041/RMMJ.10168

Copyright: (C) 2014 Greer et al. This is an open-access article. All its content, except where otherwise noted, is distributed under the terms of the Creative Commons Attribution License (http://creativecommons.org/licenses/by/3.0), which permits unrestricted use, distribution, and reproduction in any medium, provided the original work is properly cited.

Conflict of interest: No potential conflict of interest relevant to this article was reported.

* To whom correspondence should be addressed. E-mail: b_brenner@rambam.health.gov.il 


\section{EPIDEMIOLOGY AND PATHOGENESIS OF PREGNANCY COMPLICATIONS}

Recurrent pregnancy loss and gestational vascular complications (GVC), including placental abruption, pre-eclampsia, and small-for-gestational age (SGA) pregnancies, are major gestational pathologies associated with detrimental maternal and fetal complications. These complications, affecting 5\%$15 \%$ of pregnant women, are attributed to decreased trophoblast invasion and chronic hypoxia due to uteroplacental underperfusion. ${ }^{1}$ The risk of recurrent pre-eclampsia is about $15 \%$ after one previous event, increasing to $30 \%$ after two consecutive pregnancies complicated by pre-eclampsia. $^{2}$ Impaired angiogenesis is reflected by the association between the clinical presentation of the disease and serum levels of soluble Flt-1 (fms-related tyrosine kinase 1) and placenta growth factor.3 Reduction in circulating levels of free soluble Flt-1 in women with pre-eclampsia could alleviate clinical signs of the syndrome.4,5 Placental abruption, defined as premature separation of a normally inserted placenta prior to delivery of the fetus, complicates $0.5 \%-1 \%$ of pregnancies and may lead to fetal death in some cases, particularly where the abruption involves more than $50 \%$ of the placenta.

\section{HEMOSTATIC CHANGES DURING NORMAL PREGNANCY AND GVC}

Pregnancy is a physiological hypercoagulable state characterized by a progressive increase in procoagulant activity, which is maximal around term. In addition, there is a profound decrease in physiologic anticoagulants, including reduction in protein $\mathrm{S}$ activity and acquired activated protein C (APC) resistance. ${ }^{6,7}$ The overall fibrinolytic activity is impaired during pregnancy but returns rapidly to normal following delivery. Levels of prothrombin fragment $1+2$, thrombin-antithrombin complexes, and D-dimer increase as pregnancy progresses. ${ }^{8}$ These changes are considered to prepare the mother for the hemostatic challenge of delivery.

Changes in the hemostatic system can lead to excessive uteroplacental thrombosis. Reduced placental perfusion due to failed vascular remodeling within the placental bed in early pregnancy is a hallmark of pre-eclampsia. Concentrations of tissue factor (TF) and free tissue factor pathway inhibitor (TFPI) are significantly increased in maternal plasma of pre-eclamptic women compared with normal pregnancy, ${ }^{9}$ while the TFPI-to-TF ratio is significantly lower in patients with pre-eclampsia than in normal pregnancy. The acquired changes in the physiological anticoagulant system are associated with increased thrombin generation and reduced birth-weight. ${ }^{10}$ Furthermore, higher maternal plasma concentrations of plasminogen activator inhibitor-1 (PAI-1) are observed in preeclampsia compared to normal pregnancy.

\section{THROMBOPHILIA AND FETAL LOSS}

Acquired thrombophilia is associated with an increased risk of fetal loss, mainly in the first trimester, as observed in women with essential thrombocythemia. The obstetric definition of antiphospholipid syndrome (APLS) includes fetal loss at week 10 or later and recurrent consecutive embryonic losses (before week 10). It is currently thought that TF on maternal neutrophils is critical for the pathogenesis of APL-induced fetal loss, suggesting functional linkage between complement component $\mathrm{C}_{5} \mathrm{a}, \mathrm{TF}$, and neutrophil activation with subsequent decidual damage and fetal wastage. ${ }^{11}$

\section{Hereditary Thrombophilias}

It is well-established that thrombophilia increases the risk of thrombosis. Several reviews and metaanalyses have attempted to assess the association between thrombophilic risk factors and gestational vascular complications..$^{12,13}$ The major findings of the TREATS study, which systematically reviewed the area, ${ }^{13}$ point toward a modest increase in the relative risk, including a higher risk for a late pregnancy loss in the third trimester; stronger associations with recurrent pregnancy loss; and a higher risk of second trimester loss than of recurrent first trimester loss for factor V Leiden (FVL) and FII 20210A heterozygotes. However, differences in design and conduct of the studies included in this systematic review and meta-analysis limited the conclusions. A meta-analysis of prospective cohort studies, providing a superior methodological design, demonstrated that the probability of pregnancy loss in FVL women was $52 \%$ higher, but this study had insufficient power to detect increased risks in women with FII 20210A polymorphism. ${ }^{14}$

In the absence of clear and compelling evidence linking hereditary thrombophilias to pregnancy loss, and with no proven effective intervention, routine screening of pregnant women for hereditary thrombophilia is not recommended; however, screening of women with previous complications possibly associated with thrombophilia remains a matter of debate. 


\section{THROMBOPHILIA AND GESTATIONAL VASCULAR COMPLICATIONS}

The current data regarding the association of hereditary thrombophilia and GVCs are heterogeneous, and lack systematic integration of severity and co-factors. Nonetheless, these data demonstrate modest positive odds ratios for an association. Identifying a clear association opens up the possibility of antithrombotic interventions, therefore screening of previously symptomatic women will depend on conclusive therapeutic developments in women harboring thrombophilia.

While the global risk of placental abruption was found to be significant for a heterozygous FVL or a heterozygous FII 20210A polymorphism, ${ }^{13}$ this result was not reproduced in prospective studies. ${ }^{14}$ An analysis of 22 publications showed an association of placental abruption with FVL and FII 20210A polymorphism. ${ }^{15}$ A recent prospective Canadian cohort study demonstrated that carriers of FVL or prothrombin gene mutation (PGM) are not at significantly increased risk of placenta-mediated complications. ${ }^{16}$ Thus, future collaborative efforts should focus on women with a history of severe pregnancy complications with clear definitions to create a more homogeneous study group.

\section{Placental Hemostasis}

Tissue factor is essential for embryogenesis, angiogenesis, invasion, and implantation. While TF is not presented on cells that are in contact with systemic circulation, the placental surface is in direct contact with maternal circulation, and trophoblast cells constitutively express high levels of TF. ${ }^{17,18}$ In addition, cytotrophoblast differentiation and fusion to syncytiotrophoblasts require initiation of apoptosis and exposure of negatively charged phospholipids on their membrane surface. ${ }^{19}$ The need for immediate inhibition of hemorrhage in the placental intervillous spaces during gestation, labor, and delivery explains the procoagulant nature of placental trophoblast and decidual cells.

Tissue factor levels are regulated by a variety of physiological anticoagulants, including TFPI, endothelial protein $\mathrm{C}$ receptor, thrombomodulin, and annexin $\mathrm{V}$.

Tissue factor pathway inhibitor is produced and pooled in the microvascular endothelial cells and in trophoblast cells ${ }^{18}$ and is highly expressed in placental tissues from the 10th week of pregnancy up to term. ${ }^{20}$ Low-molecular-weight heparins (LMWHs) stimulate expression, synthesis, and release of TFPI in endothelial cells and may exert their effect in pregnant women at risk for GVC, by modulating local hemostasis at the placental syncytiotrophoblast surface. ${ }^{20}$

\section{Microparticles in Normal Pregnancy and GVC}

Microparticles, shed from cell membranes upon activation or apoptosis, are involved in thrombosis, inflammation, and vascular dysfunction and may play an essential role in the maternal-placental cross-talk. ${ }^{21}$

Microparticles obtained from healthy pregnant women demonstrate high procoagulant activity compared to non-pregnant females. The procoagulant activity further increases in microparticles of women with GVC without a change in the TF expression, but with reduction in TFPI. ${ }^{22}$ A hemostatic balance, manifested by the TF/TFPI ratio on microparticles originating from maternal and placental cells, could reflect normal gestational hypercoagulability as well as the vascular injury characterizing GVC pathology. ${ }^{22}$

Trophoblast differentiation yields substantial shedding of TF-bearing microparticles. Syncytiotrophoblast microparticles circulating in maternal blood can lead to endothelial dysfunction, monocyte stimulation, and excessive maternal inflammatory reaction. ${ }^{23}$

\section{ANTICOAGULANT THERAPY DURING GESTATION}

A review of about 2,800 treated pregnancies, evaluating safety and efficacy of LMWH in pregnancy, concluded that LMWH is the anticoagulant of choice during pregnancy. ${ }^{24}$

\section{Antithrombotics for Prevention of Pregnancy Loss}

The role of LMWH in the prevention of pregnancy complications remains uncertain. This possibility was stimulated by a single-center study 25 that demonstrated, in women with thrombophilia and one previous pregnancy loss after 10 weeks of gestation, that the use of enoxaparin (40 $\mathrm{mg}$ daily) resulted in a significantly better live birth rate compared to patients on low-dose aspirin (86\% versus $29 \%$, respectively). The multicenter, prospective, 
randomized LIVE-ENOX study compared two doses of enoxaparin in women with thrombophilia and a history of pregnancy loss and did not demonstrate a difference in live birth rates between the two dosages $(84 \%$ for the $40 \mathrm{mg} / \mathrm{d}$ group and $78 \%$ for the $80 \mathrm{mg} / \mathrm{d}$ group). ${ }^{26}$ Another study comparing enoxaparin $40 \mathrm{mg} / \mathrm{d}$ to low-dose aspirin, reported a similar live birth rate in women with unexplained pregnancy loss in whom thrombophilia was excluded. ${ }^{27}$ Two recent prospective multicenter randomized trials, ALIFE and SPIN, reported that antithrombotic prophylaxis did not improve pregnancy outcome in women with at least two unexplained pregnancy losses. ${ }^{28,29}$ However, thrombophilia cases were a small minority in these trials, and the majority of cases of unexplained pregnancy loss could be attributed to other causes, including aneuploidy. Therefore, the women studied would have been heterogeneous in terms of the underlying cause of the loss such that antithrombotic treatment would have been unlikely to have been beneficial in the absence of a thrombotic mechanism for their loss.

\section{Antithrombotics for Prevention of Gestational Vascular Complications}

A Canadian randomized trial compared dalteparin 5,000 units/d versus no prophylaxis in 110 women without identifiable thrombophilia who had prior placental-mediated complications. ${ }^{30}$

Dalteparin was associated with a lower rate of composite primary outcome (severe pre-eclampsia, birth-weight less than the $5^{\text {th }}$ percentile, major placental abruption) which occurred in $5.5 \%$ of those in the dalteparin arm compared to $23.6 \%$ in the no prophylaxis arm (OR 0.15 , 95\% CI $0.03-$ $0.70, P=0.016)$. A single-center randomized study 31 in women with a prior placental abruption demonstrated that prophylaxis with enoxaparin significantly reduced the primary composite outcome (31.3\% versus $12.5 \%$ ). Subsequent studies will be required to confirm these findings.

The recently published HAPPY trial, which had heterogeneous inclusion criteria, ${ }^{32}$ found no difference between intervention with LMWH (nadroparin) and the non-interventional arm for pregnancy outcome. Potential limitations of this negative trial included under-representation of severe preeclampsia, lack of information on the gestational age at the previous and present occurrence of preeclampsia, and on the number of cases of pre- eclampsia associated with fetal growth restriction/ small for gestational age (FGR/SGA). 33

The FRUIT study of women with heritable thrombophilia and early-onset pre-eclampsia demonstrated that adding LMWH to low-dose aspirin reduced recurrent pre-eclampsia onset before 34 weeks of gestation, but with no impact on general recurrence rates or overall outcome irrespective of gestational age. 34

A recent Cochrane review 35 of 14 studies assessed treatment with heparin for women considered to be at particularly high risk of pregnancy complications secondary to placental insufficiency. This review found an association with a statistically significant reduction in risk of perinatal mortality (RR 0.40, 95\% CI 0.20-0.78), preterm birth before 34 (RR $0.46,95 \%$ CI $0.29-0.73)$ and 37 weeks of gestation (RR 0.72, 95\% CI 0.58-0.90), and birth-weight below the 1oth centile for gestational age (RR 0.41 , 95\% CI 0.27-0.61), when compared with no treatment. A recent meta-analysis of LMWH for prevention of recurrent placenta-mediated pregnancy complications (PMPCs) performed in six randomized controlled studies which had included 848 pregnant women with prior PMPCs concluded that LMWH may be a promising therapy for secondary prophylaxis, especially for severe or early pre-eclampsia (RR 0.16, 95\% CI 0.07-0.36). ${ }^{36}$

Recently, the TIPPS trial-a multicenter openlabel randomized study evaluating an antepartum prophylactic dose of dalteparin versus no dalteparin in women with increased-risk pregnancy and thrombophilia-showed no benefit for the intervention arm. ${ }^{37}$ Of note, this study is characterized by a large variety of indications and a small number of patients at high risk due to previous severe placentamediated complications, likely making the study population heterogeneous for the disease mechanism.

\section{FUTURE PERSPECTIVES}

Currently, we lack data on genome-wide association study (GWAS), biomarkers, and interventions applied to specific homogeneous populations. Defining and targeting specific disease processes amenable to antithrombotics and measuring the biological response as well as the clinical outcome will be valuable in advancing this field. Future studies should focus on examining antithrombotic interventions versus placebo (or suitable control) in 
more homogeneous populations such as thrombophilic women with well-characterized severe pregnancy complications, or those stratified by pathological findings, such as a severely infarcted placenta or validated biomarkers of the disease process.

In summary, prevention of placenta-mediated complications remains a major health issue. Prospective interventional studies based on data on the pathophysiological mechanisms and systemic hemostatic alterations will pave the way for a better management of women and fetuses at risk.

\section{REFERENCES}

1. Wilcox AJ, Weinberg CR, O'Connor JF, et al. Incidence of early loss of pregnancy. $\mathrm{N}$ Engl $\mathrm{J}$ Med 1988;319:189-94. Full Text

2. Hernandez-Diaz S, Toh S, Cnattingius S. Risk of preeclampsia in first and subsequent pregnancies: prospective cohort study. BMJ 2009;338:b2255. Full Text

3. Levine RJ, Maynard SE, Qian C, et al. Circulating angiogenic factors and the risk of preeclampsia. $\mathrm{N}$ Engl J Med 2004;350:672-83. Full Text

4. Ahmed A, Cudmore MJ. Can the biology of VEGF and haem oxygenases help solve pre-eclampsia? Biochem Soc Trans 2009;37(Pt 6):1237-42. Full Text

5. Ahmed A. New insights into the etiology of preeclampsia: identification of key elusive factors for the vascular complications. Thromb Res 2011;127(Suppl 3):S72-5. Full Text

6. Cumming AM, Tait RC, Fildes S, et al. Development of resistance to activated protein $\mathrm{C}$ during pregnancy. Br J Haematol 1995;90:725-7. Full Text

7. Clark P, Brennand J, Conkie JA, et al. Activated protein $\mathrm{C}$ sensitivity, protein $\mathrm{C}$, protein $\mathrm{S}$ and coagulation in normal pregnancy. Thromb Haemost 1998;79:1166-70.

8. Sarig G, Klil-Drori AJ, Chap-Marshak D, et al. Activation of coagulation in amniotic fluid during normal human pregnancy. Thromb Res 2011;128:490-5.

9. Erez O, Romero R, Hoppensteadt D, et al. Tissue factor and its natural inhibitor in pre-eclampsia and SGA. J Matern Fetal Neonatal Med 2008;21:855-69. Full Text

10. Clark P, Walker ID, Greer I. Acquired activated protein-C resistance in pregnancy and association with increased thrombin generation and fetal weight. Lancet 1999;353:292-3. Full Text

11. Redecha P, Tilley R, Tencati M, et al. Tissue factor: a link between $\mathrm{C}_{5} \mathrm{a}$ and neutrophil activation in anti- phospholipid antibody induced fetal injury. Blood 2007;110:2423-31. Full Text

12. Dudding TE, Attia J. The association between adverse pregnancy outcomes and maternal factor V Leiden genotype: a meta-analysis. Thromb Haemost 2004;91:700-11.

13. Robertson L, Wu O, Langhorne P, et al. Thrombophilia in pregnancy: a systematic review. $\mathrm{Br} \mathrm{J}$ Haematol 2006;132:171-96. Full Text

14. Rodger MA, Betancourt MT, Clark P, et al. The association of factor $\mathrm{V}$ leiden and prothrombin gene mutation and placenta-mediated pregnancy complications: a systematic review and meta-analysis of prospective cohort studies. PLoS Med 2010;7: e1000292. Full Text

15. Zdoukopoulos N, Zintzaras E. Genetic risk factors for placental abruption: a HuGE review and metaanalysis. Epidemiology 2008;19:309-23. Full Text

16. Rodger MA, Walker MC, Smith GN, et al. Is thrombophilia associated with placenta-mediated pregnancy complications? A prospective cohort study. J Thromb Haemost 2014;12:469-78. Full Text

17. Sood R, Kalloway S, Mast AE, et al. Fetomaternal cross talk in the placental vascular bed: control of coagulation by trophoblast cells. Blood 2006; 107:3173-80. Full Text

18. Aharon A, Brenner B, Katz T, et al. Tissue factor and tissue factor pathway inhibitor levels in trophoblast cells: implications for placental hemostasis. Thromb Haemost 2004;92:776-86.

19. Huppertz B, Kadyrov M, Kingdom JC. Apoptosis and its role in the trophoblast. Am J Obstet Gynecol 2006;195:29-39. Full Text

20. Aharon A, Lanir N, Drugan A, Brenner B. Placental TFPI is decreased in gestational vascular complications and can be restored by maternal enoxaparin treatment. J Thromb Haemost 2005;3:2355-7. Full Text

21. Shomer E, Katzenell S, Zipori Y, et al. Microvesicles of women with gestational hypertension and preeclampsia affect human trophoblast fate and endothelial function. Hypertension 2013;62:893-8. Full Text

22. Aharon A, Katzenell S, Tamari T, Brenner B. Microparticles bearing tissue factor and tissue factor pathway inhibitor in gestational vascular complications. J Thromb Haemost 2009;7:1047-50. Full Text

23. Germain SJ, Sacks GP, Sooranna SR, et al. Systemic inflammatory priming in normal pregnancy and preeclampsia: the role of circulating syncytiotrophoblast microparticles. J Immunol 2007;178:5949-56. Full Text 
24. Greer IA, Nelson-Piercy C. Low-molecular-weight heparins for thromboprophylaxis and treatment of venous thromboembolism in pregnancy: a systematic review of safety and efficacy. Blood 2005;106:401-7. Full Text

25. Gris JC, Mercier E, Quere I, et al. Low-molecularweight heparin versus low-dose aspirin in women with one fetal loss and a constitutional thrombophilic disorder. Blood 2004;103:3695-9. Full Text

26. Brenner B, Hoffman R, Carp H, et al. Efficacy and safety of two doses of enoxaparin in women with thrombophilia and recurrent pregnancy loss: the LIVE-ENOX study. J Thromb Haemost 2005;3:2279. Full Text

27. Dolitzky M, Inbal A, Segal Y, et al. A randomized study of thromboprophylaxis in women with unexplained consecutive recurrent miscarriages. Fertil Steril 2006;86:362-6. Full Text

28. Clark P, Walker ID, Langhorne P, et al. SPIN (Scottish Pregnancy Intervention) study: a multicenter, randomized controlled trial of low-molecularweight heparin and low-dose aspirin in women with recurrent miscarriage. Blood 2010;115:4162-7. Full Text

29. Kaandorp SP, Goddijn M, van der Post JA, et al. Aspirin plus heparin or aspirin alone in women with recurrent miscarriage. N Engl J Med 2010;362:158696. Full Text

30. Rey E, Garneau P, David M, et al. Dalteparin for the prevention of recurrence of placental-mediated complications of pregnancy in women without thrombophilia: a pilot randomized controlled trial. J Thromb Haemost 2009;7:58-64. Full Text

31. Gris JC, Chauleur C, Faillie JL, et al. Enoxaparin for the secondary prevention of placental vascular complications in women with abruptio placentae. The pilot randomised controlled NOH-AP trial. Thromb Haemost 2010;104:771-9. Full Text

32. Martinelli I, Ruggenenti P, Cetin I, et al. Heparin in pregnant women with previous placenta-mediated pregnancy complications: a prospective, randomized, multicenter, controlled clinical trial. Blood. 2012;119:3269-75. Full Text

33. Gris JC, Bouvier S, Molinari N, et al. Comparative incidence of a first thrombotic event in purely obstetric antiphospholipid syndrome with pregnancy loss: the NOH-APS observational study. Blood. 2012;119:2624-32. Full Text

34. de Vries JI, van Pampus MG, Hague WM, et al. Lowmolecular-weight heparin added to aspirin in the prevention of recurrent early-onset pre-eclampsia in women with inheritable thrombophilia: the FRUITRCT. J Thromb Haemost 2012;10:64-72. Full Text

35. Dodd JM, McLeod A, Windrim RC, Kingdom J. Antithrombotic therapy for improving maternal or infant health outcomes in women considered at risk of placental dysfunction. Cochrane Database Syst Rev 2013;7:CDoo6780.

36. Rodger MA, Carrier M, Le Gal G, et al. Meta-analysis of low-molecular-weight heparin to prevent recurrent placenta-mediated pregnancy complications. Blood 2014;123:822-8. Full Text

37. Rodger MA, Hague WM, Kingdom J, et al. Antepartum dalteparin versus no antepartum dalteparin for the prevention of pregnancy complications in pregnant women with thrombophilia (TIPPS): a multinational open-label randomised trial. Lancet 2014 Jul 24. [Epub ahead of print]. Full Text 